\title{
PEMODELAN KELUHAN KELELAHAN MATA PENGRAJIN KERAWANG MENGGUNAKAN REGRESI LOGISTIK
}

\author{
Reni Hiola $^{(1)}$, RamaHiola ${ }^{(2)}$ \\ ${ }^{(1)(2)}$ Faculty Science Health and Sportmanship, University Country of Gorontalo, Gorontalo \\ e-mail: ${ }^{1}$ hiola.reni@gmail.com, ${ }^{2}$ hiola.rama@gmail.com
}

\begin{abstract}
ABSTRAK
Tujuan penelitian ini adalah mengkaji faktor-faktor yang mempengaruhi kelelahan mata berdasarkan keluhan pengrajin kerawang di Kabupaten Gorontalo menggunakan regresi logistik. Hasil penelitian menunjukkan bahwa kelelahan mata berdasarkan keluhan pada pengrajin kerawang terdapat hubungan dengan arah sinar, dengan warna dinding. Kelelahan mata berdasarkan keluhan pengrajin kerrawang dipengaruhi oleh umur, arah sinar lebih dari 30 derajat, warna dinding putih dan intensitas dengan ketepatan klasifikasi sebesar 74.6 persen.
\end{abstract}

Kata kunci : Kelelahan mata,Keluhan, Regresi Logistik, Ketepatan Klasifikasi.

\section{PENDAHULUAN}

Penerangan (iluminasi) menurut (Siswanto, A dan Witosetijoso,1988) adalah banyaknya cahaya yang jatuh pada suatu permukaan. Pencahayaan adalah segala hal yang berhubungan dengan cahaya dalam kaitannya dengan fungsi penglihatan dalam pekerjaan, meliputi kualitas dan kuantitas(Cok Gd. Rai Padmanaba,2006). Baik tidaknya penerangan disuatu tempat kerja selain ditentukan oleh kuantitas atau tingkat iluminasi yang menyebabkan obyek dan sekitarnya terlihat dengan jelas, ditentukan juga oleh kualitas dari penerangan tersebut yang diantaranya menyangkut arah dan penyebaran/distribusi cahaya, tipe dan tingkat kesilauan (Ridley, J., 2006).

Pencahayan/penerangan yang penting untuk melakukan pekerjaan sering diabaikan, hasil survei intensitas penerangan (iluminasi) di ruangan rata-rata kurang dari standar 300 lux dan penerangannya tidak merata(Hughes, P.C and J.F.Mc Nelis, 1978). Secara teori, kondisi ini dapat menyebabkan kelelahan mata pada pengrajin, sementara pekerjaan ini memerlukan ketelitian dan termasuk pekerjaan amat halus, sehingga membutuhkan tingkat pencahayaan 500 sampai 1000 lux sesuai dengan Peraturan Menteri Perburuhan (PMP No.7 Tahun 1964) tentang syaratsyarat kesehatan, kebersihan serta penerangan dalam tempat kerja(Prabu, 2009).

Menurut (Siswanto, A dan Witosetijoso, 1988), ada tiga metode penerangan, yaitu: penerangan umum, penerangan lokal dan penerangan cahaya aksen. Penerangan umum atau baur menerangi ruangan secara merata dan umumnya terasa baur. Penerangan lokal atau penerangan untuk kegunaan khusus, menerangi sebagian ruang dengan sumber cahaya biasanya dipasang dekat dengan permukaan yang diterangi. sedangkan penerangan aksen adalah bentuk dari pencahayaan lokal yang berfungsi menyinari suatu tempat atau aktivitas tertentu atau obyek seni atau koleksi berharga lainnya. Bila persepsi visual mengalami stress yang hebat tanpa disertai efek local pada otot akomodasi atau retina maka keadaan ini akan menimbulkan kelelahan syaraf. General Nervus Fatique ini terutama akan terjadi bila pekerjaan yang dilakukan seseorang memerlukan kosentrasi,control otot dan gerakan-gerakan yang sangat tepat. Gejala-gejala kelelahan mata tersebut menyebabkan utamanya adalah penggunaan otototot disekitar mata yang berlebihan. Kelelahan mata dapat dikurangi dengan memberikan pencahayaan yang baik ditempat kerja(Hughes, P.C and J.F.Mc Nelis, 1978).

Penerangan yang baik memungkinkan tenaga kerja melihat objek yang dikerjekannya secara jelas, cepat dan tanpa upaya yang tidak perlu. Lebih dari itu, penerangan yang memadai memberikan kesan pemandangan yang lebih baik dan keadaan lingkungan yang menyegarkan.

Menurut (Cok Gd. Rai Padmanaba, 2006), kelelahan mata dapat dipengaruhi dari kuantitas iluminasi, kualitas iluminasi dan distribusi cahaya. Kualitas iluminasi adalah tingkat pencahayaan yang dapat berpengaruh pada kelelahan mata,penerangan yang tidak memadai akan menyebabkan otot iris mengatur pupil sesuai dengan intensitas penerangan

Reni Hiola ${ }^{1}$, RamaHiola ${ }^{2}$ / J Statistika Vol. 9, No. 1, (2016) 
yang ada. Kualitas iluminasi meliputi jenis penerangan,sifat fluktuasi serta warna penerangan yang digunakan. Distribusi cahaya yang kurang baik dilingkungan kerja dapat menyebabkan kelalahan mata. Distribusi cahaya yang tidak merata sehingga menurunkan efisiensi tajam penglihatan dan kemampuan membedakan kontras (Hughes, P.C and J.F.Mc Nelis, 1978).

Kelelahan mata akibat dari pencahayaan yang kurang baik akan menunjukan gejala kelelahan mata yang sering muncul antara lain: Kelopak mata terasa berat,terasa ada tekanan dalam mata sedikit ditekan,bagian mata paling dalam terasa sakit,perasaan mata berkedip,penglihatan kabur,tidak bias difokuskan,penglihatan tersa silau,penglihatan seperti berkabut walau mata difokuskan,mata mudah berair,mata pedih dan berdenyut,mata merah,jika mata ditutup terlihat kilatan cahaya,kotoran mata bertambah,tidak dapat membedakan warna sebagaimana biasanya,ada sisa bayangan dalam mata,penglihatan tampak double,mata tersa panas,mata terasa kering (Soewarno,1992).

Dalam kaitannya dengan kegiatan pengrajin kerawang yang dilakukan, perlu untuk mengkaji factor apa yang mempengaruhi kelelahan mata (Hiola, R. and Bambang W. O., 2015) berdasarkan keluhan pengrajin karawang Kabupaten Gorontalo menggunakan regresi logistic.

\section{METODE PENELITIAN}

Penelitian ini dilakukan secara cross sectional, yang dilakukan melalui 3 tahap: Observasi dan studi referensi mengenai sistim penerangan industri pengrajin kerawang. Hasil observasi dan studi referensi di tahap pertama menjadi dasar penyusunan panduan wawancara untuk mengetahui variabel faktor penerangan optimal (TOHEREN) pada pengrajin kerawang Kabupaten Gorontalo. Penilaian tingkat akurasi kelelahan mata responden sebagai hasil wawancara dengan menggunakan alat pengukur Flicker Frequency. Menentukan model Sistem Penerangan Toheren (Tohe Mokarawo Ergonomi) pada pengrajin kerawang di Kabupaten Gorontalo. Kelelahan Mata berdasarkan keluhan dipengaruhi oleh karakteristik pengrajin kerawang (umur, pendidikan, masa kerja dan waktu kerja), penerangan (iluminasi) (silau (glare), arah sinar, bayangan, warna, jarak pandang dan suhu)(Hiola, R. and Bambang W. O., 2015)(Hiola, Reni. and Hiola Rama, 2015). Analisis data yang digunakan adalah regresi logistik biner dengan estimasi parameter Maksimum Likelihood Estimation (MLE) selanjutnya uji parameter baik secara serentak maupun parsial, serta melakukan uji kesesuaian model.

\section{HASIL DAN PEMBAHASAN}

Hubungan variable bayangan, arah sinar, dan warna dinding dengan keluhan kelelahan matamenggunakan statistic uji Chi-Square disajikan pada Tabel berikut.

Tabel 1.Deskripsi \&uji independensi keluhan kelelahan matadengan variabel independen

\begin{tabular}{|c|c|c|c|}
\hline \multirow{2}{*}{\multicolumn{2}{|c|}{$\begin{array}{l}\text { Frekuensi } \\
\text { \% Total } \\
\text { Pearson Chi-Square }\end{array}$}} & \multicolumn{2}{|c|}{ Keluhan Kelelahan Mata } \\
\hline & & \multirow{2}{*}{$\begin{array}{c}\begin{array}{c}\text { Tidak } \\
\text { Ada } \\
\text { Keluhan }\end{array} \\
5 \\
(7.0)\end{array}$} & \multirow{2}{*}{$\begin{array}{r}\begin{array}{c}\text { Ada } \\
\text { Keluhan }\end{array} \\
13 \\
(18.3)\end{array}$} \\
\hline \multirow{3}{*}{$\begin{array}{l}\text { Bayang } \\
\text { an }\end{array}$} & Ada & & \\
\hline & Tidak ada & $\begin{array}{r}21 \\
(29.6)\end{array}$ & $\begin{array}{r}32 \\
(45.1)\end{array}$ \\
\hline & \multicolumn{3}{|c|}{$\begin{array}{l}\text { Pearson Chi-Square }=0.812 \mathrm{df}=1 \\
\text { Asymptotic Significance }(2 \text {-sided })=0.367\end{array}$} \\
\hline \multirow{3}{*}{$\begin{array}{l}\text { Arah } \\
\text { Sinar }\end{array}$} & $>30$ derajat & $\begin{array}{r}8 \\
(11.3)\end{array}$ & $\begin{array}{r}29 \\
(40.8)\end{array}$ \\
\hline & $<30$ derajat & $\begin{array}{r}18 \\
(25.4)\end{array}$ & $\begin{array}{r}16 \\
(22.5)\end{array}$ \\
\hline & \multicolumn{3}{|c|}{$\begin{array}{l}\text { Pearson Chi-Square }=7.488 \mathrm{df}=2 \\
\text { Asymptotic Significance }(2 \text {-sided })=0.006\end{array}$} \\
\hline \multirow{3}{*}{$\begin{array}{l}\text { Warna } \\
\text { Dinding }\end{array}$} & Putih & $\begin{array}{r}17 \\
(23.9)\end{array}$ & $\begin{array}{r}40 \\
(56.3)\end{array}$ \\
\hline & Berwarna & $\begin{array}{r}9 \\
(12.7)\end{array}$ & $\begin{array}{r}5 \\
(7.0)\end{array}$ \\
\hline & \multicolumn{3}{|c|}{$\begin{array}{l}\text { Pearson Chi-Square }=5.751 \mathrm{df}=1 \\
\text { Asymptotic Significance }(2 \text {-sided })=0.016\end{array}$} \\
\hline
\end{tabular}

Tabel 1 menunjukan bahwa sebagian besar pengrajin kerrawang tidak mengalami keluhan pada kelelahan mata, yaitu sebesar 36.4 persen, dan ada keluhan kelelahan mata sebesar 63.4 persen. Selain itu dapat ditunjukkan bahwa semua nilai Asymptotic Significance (2-sided) lebih kecil dari $\alpha=0.05$ maka terdapat hubungan antara keluhan kelelahan mata dengan arah sinar, dengan warna dinding. Sedangkan dengan bayangan tidak terdapat hubungan.

Selanjutnya estimasi parameter model regresi logistic biner dengan metode Maximum Likelihood Estimation (MLE) disajikan pada Tabel 2.

Tabel 2. Estimasi Parameter Model Regresi Logistik Pada Keluhan Kelelahan Mata

\begin{tabular}{|c|l|c|c|c|c|c|}
\hline \multirow{3}{*}{$\begin{array}{l}\mathbf{N} \\
\mathbf{0}\end{array}$} & \multirow{2}{*}{$\begin{array}{l}\text { Variab } \\
\text { el }\end{array}$} & $\begin{array}{c}\text { Est } \\
\text { im } \\
\text { ate }\end{array}$ & $\begin{array}{c}\text { Std } \\
\text { Err } \\
\text { or }\end{array}$ & $\begin{array}{c}\text { Wa } \\
\text { ld }\end{array}$ & Sig. & $\begin{array}{c}\text { Exp( } \\
\text { B) }\end{array}$ \\
\hline 1 & Umur & -.429 & .166 & 6.687 & .010 & .651 \\
\hline
\end{tabular}

Reni Hiola ${ }^{1}$, RamaHiola ${ }^{2}$ J Statistika Vol. 9, No. 1, (2016) 


\begin{tabular}{|c|l|r|r|r|r|c|}
\hline 2 & $\begin{array}{l}\text { Baya } \\
\text { ngan } \\
(1)\end{array}$ & -.817 & .867 & .888 & .346 & .442 \\
\hline 3 & $\begin{array}{l}\text { Arah } \\
(1)\end{array}$ & 3.741 & 1.325 & 7.973 & .005 & $\begin{array}{c}42.12 \\
2\end{array}$ \\
\hline 4 & Jarak & .159 & .106 & 2.242 & .134 & 1.172 \\
\hline 5 & $\begin{array}{l}\text { Warna } \\
(1)\end{array}$ & 3.999 & 1.852 & 4.664 & .031 & $\begin{array}{c}54.52 \\
0\end{array}$ \\
\hline 6 & $\begin{array}{l}\text { Inten } \\
\text { sitas }\end{array}$ & .029 & .013 & 5.173 & .023 & 1.029 \\
\hline $\begin{array}{l}\text { Omnibus Tests of Model Coefficients, Chi-square }= \\
\text { 22.515, Sig. = 0.001 }\end{array}$ \\
\hline
\end{tabular}

Tabel 2 menunjukkan bahwa nilai Omnibus Test dapat diketahui bahwa Pvalue yang dihasilkan oleh keenam variabel tersebut yaitu umur, bayangan, arah sinar, jarak, warna dan intensitas sebesar Sig. = 0,000 lebih kecil dari $\alpha=0.05$ sehingga diperoleh keputusan yaitu $\mathrm{H}_{0}$ tolak maka dapat memberi informasi bahwa keenam variabel tersebut berpengaruh signifikan terhadap keluhan kelelahan mata secara serentak. Selanjutnya secara parsial dengan metode MLE bahwa variabel umur, bayangan dan jarak tidak signifikan dalam mempengaruhi keluhan kelelahan mata pengrajin kerrawang, karena nilai Sig. (p-value) lebih besar dari $\alpha=0.10$. Sedangkan variable $\operatorname{arah}(1)$, warna (1) dan intesitas signifikan dalam mempengaruhi keluhan kelelahan mata pengrajin kerrawang karena nilai Sig. (p-value) lebih besar dari $\alpha=0.05$. Model regresi logistic biner dengan metode Maximum Likelihood Estimation (MLE) dapat diperoleh nilai peluang dari tiap kategorik pada variable keluhan kelelahan mata, yaitu sebagai berikut.

$$
\begin{aligned}
& \pi(x)=\frac{\exp (g(x))}{1+\exp (g(x))} \\
= & \frac{\mathrm{e}^{(-0,429 \text { Umur- } 0,817 \text { Bayangan(1)+3.741Arah(1)+0.159Jarak +3.999Warna(1)+0.029Intensitas) }}}{1+\mathrm{e}^{(-0,429 \text { Umur-0,817Bayangan(1)+3.741Arah(1)+0.159Jarak+3.9999Warna(1)+0.029Intensitas) }}}
\end{aligned}
$$

Uji kesesuaian model digunakan untuk mengetahui apakah terdapat perbedaan antara hasil observasi dengan kemungkinan hasil prediksi. Hipotesis yang digunakan adalah sebagai berikut.

$\mathrm{H}_{0}$ : model sesuai (tidak ada perbedaan antara hasil observasi dengan kemungkinan hasil prediksi)

$\mathrm{H}_{1}$ : model tidak sesuai (ada perbedaan antara hasil observasi dengan kemungkinan hasil prediksi)

Tingkat signifikasi yang digunakan adalah $5 \%$. Statistik uji yang digunakan adalah statistik uji $\hat{C}$ yang dihitung dari Hosmer and Lemeshow test diperoleh nilai $\hat{C}$ yaitu 8.619 dimana nila iini lebih kecil dari $\chi_{8,0.05}^{2}=15.50731$ atau Sig. (Pvalue) yang dihasilkan adalah 0,375 lebih kecil $\alpha=0.05$ dari sehingga menghasilkan keputusan $\mathrm{H}_{0}$ gagal tolak maka model sesuai (tidak terdapat perbedaan yang signifikan antara hasil pengamatan dengan kemungkinan hasil prediksi model). Dengan demikian, model regresi serentak yang diperoleh sesuai untuk menjelaskan seberapa besar peluang pengrajin kerawang yang mempunyai keluhan.

Tabel klasifikasi merupakan cara lain yang menarik untuk menyatakan kelayakan suatu model yaitu seberapa besar persentase observasi secara tepat diklasifikasikan. Hasil tabel ini berupa klasifikasi silang dari variabel respon dengan skala dikotomus sebagaimana ditunjukkan pada Tabel berikut

Tabel 3. Ketepatan Klasifikasi Keluhan Kelelahan Mata

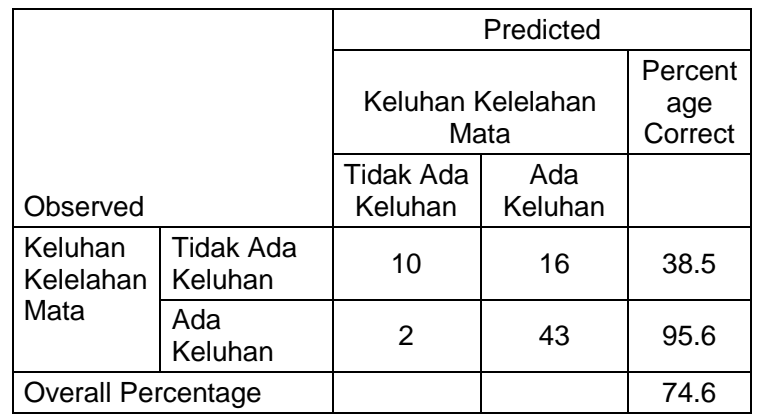

Berdasarkan Tabel 3 dapat diketahui bahwa Overall Percentage yang dihasilkan oleh keenam variabel tersebut yaitu umur, bayangan, arah sinar, jarak, warna dan intensitas sebesar 74.6 maka dapat memberi informasi bahwa ketepatan klasifikasi keluhan kelelahan mata berdasarkan keenam variabel tersebut sebesar 74.6 persen,dan besarnya misklasifikasi (APER) adalah 25,4 persen.

\section{KESIMPULAN DAN SARAN}

Berdasarkan hasil dan pembahasan maka dapat disimpulkan bahwa kelelahan mata berdasarkan keluhan pengrajin kerawang terdapat hubungan dengan variabel pada saat bekerja dan lingkungannya, yaitu umur, bayangan, arah sinar, jarak, warna dan intensitas. Pengrajin kerawang sesudah bekerja cenderung mengalami kelelahan mata dibanding sebelum bekerja. Faktor yang mempengaruhi kelelahan mata berdasarkan pengukuran keluhan adalah umur, arah sinar lebih dari 30 derajat, warna dinding putih dan intensitas dengan ketepatan klasifikasi sebesar 74.6 persen, sensitivitas 95.6 persen dan spesivisitas sebesar 38,5 persen

\section{DAFTAR PUSTAKA}

Siswanto, A dan Witosetijoso.(1988). Penerangan Balai Hiperkes dan Keselamatan Kerja, Erlangga Surabaya

Reni Hiola ${ }^{1}$, RamaHiola ${ }^{2}$ J Statistika Vol. 9, No. 1, (2016) 
Cok Gd. Rai Padmanaba, (2006). Pengaruh Penerangan Dalam Ruang Terhadap Produktivitas Mahasiswa Desain Interior.http://www.petra.ac.id/ puslit/journal s/dir.php?DepartementID=INT. Efficient Use of Electricity in Industries- Devki Energy Consultancies Pvt. Ltd., Vadodara

Ridley, J. (2006). Kesehatan danKeselamatan Kerja. Jakarta: Erlangga

Hughes, P.C and J.F.Mc Nelis.(1978). Lighting Produktiviti and The Work Enviroment. Journal of Lighting Design Aplication

Prabu, (2009). Sistem dan Standar Pencahayaan Ruang,http://putraprabu.wordpress.com/2012/ 03/06 sistem-dan-standar-pencahayaanruang.Diakses pada tanggal 6 Maret 2012.
Soewarno, (1992). Penerangan Tempat Kerja, Jakarta: Pusat Pelayanan Ergonomidan Kesker.

Hiola, R. and Bambang W. O., (2015).Standard illumination (toheren) based on flicker Fusion using adaptive regression spline on filigree Craftsman in gorontalo province. Journal of Health, Sport and Tourism ISSN: 2078-0273, Vol. 6. No. 1

Hiola, Reni. and Hiola Rama. (2015).Adaptive regression spline approach on complaints eye fatigue craftsmen Makarawo in Gorontalo

Reni Hiola ${ }^{1}$, RamaHiola $^{2}$ / J Statistika Vol. 9, No. 1, (2016) 